\title{
FLEXIBILIDADE ORGANIZACIONAL E VIVÊNCIAS DE PRAZER- SOFRIMENTO: UM ENSAIO TEÓRICO
}

\author{
Monique Nascimento ${ }^{1}$ \\ Eloise Helena Livramento Dellagnelo ${ }^{2}$ \\ Renê Birochi ${ }^{3}$
}

\section{Resumo}

Este ensaio teórico tem por objetivo discorrer a respeito das implicações da flexibilidade organizacional nas vivências de prazer-sofrimento do trabalhador. Por meio deste estudo foi possível sugerir que o atual discurso de flexibilidade organizacional, liberdade oferecida ao trabalhador e maiores vivências de prazer, pode se tratar da legitimação da dominação burocrática, adaptada a um novo contexto econômico. Nesse sentido, ressalta-se a potencialidade que os estudos organizacionais possuem na produção de um conhecimento que auxilie na subversão do sofrimento em prazer, e propõe-se a reflexão das atuais práticas hegemônicas tanto em nível organizacional quanto global para que se tente superar as atuais instrumentalidades em prol de ambientes de trabalhos e organizações mais salutares.

Palavras-chave: Vivências de prazer-sofrimento. Flexibilidade organizacional. Estudos organizacionais.

\section{ORGANIZATIONAL FLEXIBILITY AND PLEASURE-SUFFERING EXPERIENCES: A THEORETICAL ESSAY}

\begin{abstract}
This theoretical essay aims to discuss the implications of organizational flexibility in the experiences of worker pleasure and suffering. With this study was possible to suggest that the current discourse of organizational flexibility, freedom offered to the employee and higher experiences of pleasure, can treat the legitimacy of bureaucratic domination, adapted to a new economic context. In this sense, it emphasizes the potential that organizational studies have to produce a knowledge that helps in the overthrow of suffering into pleasure, and it is proposed to reflect on

\footnotetext{
1 Doutoranda do Programa de Pós-Graduação em Administração da Universidade Federal de Santa Catarina (PPGA/UFSC). Correio eletrônico: moniquenn@gmail.com.

2 Professora do Programa de Pós-Graduação em Administração da Universidade Federal de Santa Catarina (PPGA/UFSC). Correio eletrônico: eloise.livramento@ufsc.br.

3 Professor do Programa de Pós-Graduação em Administração da Universidade Federal de Santa Catarina (PPGA/UFSC). Correio eletrônico: rene.birochi@ufsc.br.
} 
current hegemonic practices at both the organizational and global levels in order to try to overcome the current instrumentalities in favor of salutary work environments and organizations.

Keywords: Experiences of pleasure-suffering. Organizational flexibility. Organizational studies.

\section{FLEXIBILIDAD ORGANIZACIONAL Y VIVENCIAS DE PLACER- SUFRIMIENTO: UN ENSAYO TEÓRICO}

\section{Resumen}

Este ensayo teórico tiene por objeto discurrir sobre las implicaciones de la flexibilidad organizacional en las vivencias de placer-sufrimiento del trabajador. Por medio de este estudio fue posible sugerir que el actual discurso de flexibilidad organizacional, libertad ofrecida al trabajador y mayores vivencias de placer, puede tratarse de la legitimación de la dominación burocrática, adaptada a un nuevo contexto económico. En ese sentido, se resalta la potencialidad que los estudios organizacionales poseen en la producción de un conocimiento que auxilie en la subversión del sufrimiento en placer, y se propone la reflexión de las actuales prácticas hegemónicas tanto a nivel organizacional cuanto global para que se intente superar las actuales instrumentalidades en favor de ambientes de trabajo y organizaciones más saludables.

Palabras clave: Vivencias de placer-sufrimiento. Flexibilidad organizacional. Estudios organizacionales.

\section{Introdução}

O imaginário social, no atual sistema econômico, tornou-se dominado pela lógica de mercado e a gestão, por sua vez, transformou-se na ciência central do atual sistema econômico, podendo ser entendida como uma vontade de domínio racional. Esse domínio não diz respeito apenas à economia, mas sim à sociedade por inteira (GAULEJAC, 2014). A família se tornou uma pequena empresa encarregada de produzir seres empregáveis, em que cada membro tem sua lição individual, aprender a 
gerir a si mesmo. O utilitarismo transformou a "sociedade em uma máquina de produção e o homem em um agente a serviço da produção" (GAULEJAC, 2014, p.79).

Conforme Marzano (2004), embora o indivíduo contemporâneo seja apresentado como o "mestre do tempo" e o tempo de trabalho flexível ofereça, pelo menos em princípio, uma possibilidade de reorganização do tempo de lazer, hodiernamente, um grande número de pessoas tem permanecido impossibilitado de "sair" do tempo de trabalho. De maneira geral, conforme o autor, parece difícil calcular o tempo que se passa trabalhando, tendo em vista que o tempo de trabalho supera os limites físicos e temporais da empresa.

No entanto, o problema não é somente relacionado aos excessos físicos e temporais do local de trabalho, mas diz respeito, principalmente, à dificuldade que alguns trabalhadores possuem em estabelecer um limite entre vida pública e privada, trabalho e demais esferas da vida cotidiana (MARZANO, 2004). Dentro deste contexto, o que se observa é que o predomínio da racionalidade instrumental e a perspectiva utilitarista assumida pelas organizações tende a negar uma dimensão essencial, a dimensão do humano (GAULEJAC, 2014; AKTOUF, 2001). A ideologia gerencialista tem transformado cada sujeito em capital humano e recurso humano, cujo comportamento deve ser flexível e adaptável às mais variadas circunstâncias (SENNET, 1999).

$\mathrm{Na}$ era da qualidade e da criatividade exige-se que cada trabalhador seja protagonista, ativo, pensante (AKTOUF, 2001), um verdadeiro empreendedor para um mundo produtivista (GAULEJAC, 2014). Nesse processo, o manager surge como verdadeiro ideal de homem que empreende, assume riscos, decide, suporta o estresse e põe todas as suas qualidades a serviço da rentabilidade (GAULEJAC, 2014). 
Contudo, a frequente interiorização do discurso do manager não permanece neutra, em relação à saúde psíquica dos trabalhadores. Pelo contrário, a interiorização desse ideário por parte dos trabalhadores, sem atenuação, possibilita que esses valores assumam uma função ideológica, que permite legitimar a angústia e o sofrimento (PAGÉS, et al., 1993). No caso de problemas de saúde agravados pelo modo de funcionamento de uma organização que desorganiza os equilíbrios de base dos trabalhadores, os custos desses efeitos "secundários" são terceirizados por exemplo, por meio da Seguridade e Previdência Social. (GAULEJAC, 2014; DEJOURS, 2012).

Diante deste contexto, salienta-se que também há, atualmente, um discurso sobre a flexibilidade organizacional, o qual está associado a ideias como capacidade de oferecer maior variabilidade de produtos aos clientes, ao uso de tecnologias de base microeletrônica, à adoção de estratégias diversas em segmentos de mercado distintos, à ênfase na inovação de produtos e processos produtivos e também à maior liberdade oferecida ao trabalhador na execução de suas tarefas e, por consequência, a um aumento da possibilidade de vivências de prazer no ambiente de trabalho. Destaca-se, no entanto, que o uso do termo flexibilidade organizacional apresenta certa ambivalência, incluindo-se aí a possibilidade de sua utilização para se fazer referência a fenômenos tanto positivos quanto negativos no trabalho.

Tais discussões sobre o aumento das chances de vivência de prazer neste novo cenário econômico provocam reflexões que podem ser enriquecidas com o aporte teórico da psicodinâmica do trabalho. Partindo da análise das questões corriqueiras do cotidiano nas organizações produtivas, a psicodinâmica do trabalho atribui relevância às vivências de prazer-sofrimento no trabalho (MENDES; ARAÚJO, 2012) e considera que 
todo trabalho pode ser tanto fonte de prazer quanto de sofrimento (MENDES; MULLER, 2013). Compreende ainda, que o sofrimento no trabalho é relacionado à falta de liberdade oferecida ao trabalhador e de flexibilidade na organização do trabalho, o qual impede que o trabalhador seja considerado sujeito do seu comportamento (DEJOURS et al., 2014).

A tese subjacente a este ensaio teórico é que o atual discurso de flexibilidade organizacional, o qual faz referência à liberdade oferecida ao trabalhador e a maiores vivências de prazer, pode se tratar da legitimação da dominação burocrática adaptada a um novo contexto, implicando, assim, no agravamento das vivências de sofrimento no trabalho. Desta forma, o seu objetivo consiste em discorrer a respeito das implicações da flexibilidade organizacional nas vivências de prazer-sofrimento do trabalhador na contemporaneidade. Para o desenvolvimento do percurso teórico do presente ensaio discutir-se-á, primeiramente, aspectos específicos aos atuais modelos de gestão, incluindo-se uma discussão sobre flexibilidade organizacional e suas distintas concepções. Posteriormente, apresentar-se-á reflexões concernentes a vivências de prazer-sofrimento no trabalho. Por fim, esboçar-se-á algumas reflexões a respeito das vivências de prazer-sofrimento no trabalho e flexibilidade organizacional. Salienta-se que não se tem aqui a pretensão de levantar exaustivamente todas as discussões sobre vivências de prazer-sofrimento no trabalho e flexibilidade organizacional, mas sim de levantar textos representativos e argumentos que contestem o discurso vigente a respeito de um cenário eminentemente positivo sobre a questão.

\section{Organizações Flexíveis}

Devido ao ambiente de negócios altamente turbulento encontrado no fim do século XX e início do século XXI, reinventar as empresas, 
flexibilizar e alcançar um retorno de curto prazo tornou-se regra. Sendo assim, as últimas décadas passaram a representar, tanto para práticas administrativas nas organizações formais, quanto para seus respectivos estudos, um período significativo de discussões, questionamentos e controvérsias a respeito de modelos e paradigmas estabelecidos (PAES DE PAULA, 2002).

Palmer et al. (2007) sugerem que o conceito de formas organizacionais alternativas ao modelo burocrático se faz presente há mais de 30 anos. No entanto, conforme os autores, apesar das discussões a respeito das novas formas organizacionais já existirem há muito tempo, é possível perceber o uso diferente da terminologia para a mesma construção ou da mesma terminologia para diferentes construções.

Dellagnelo e Machado-da-Silva (2000) referem que essas novas formas organizacionais têm sido tratadas mediante diferentes significações: desde as mais amplas (redesenho organizacional, flexibilidade organizacional, pós-modernismo, novos paradigmas na organização) até as mais específicas (organizações de aprendizagem, equipes de trabalho, redes organizacionais, empowerment). Os autores realizaram um estudo cujo objetivo foi verificar se as evidências empíricas de novos formatos organizacionais apresentadas em publicações realizadas em periódicos nacionais ou estrangeiros (de língua inglesa) durante o período de 1995 a 1998, representavam ruptura com o modelo burocrático de organização. Após análise das dimensões da tecnologia, estrutura e cultura, observaram que os inúmeros casos apresentados na literatura especializada durante o período de investigação ainda apresentavam evidências muito tênues quanto à possível ruptura com o modelo burocrático. Conforme os autores, apesar de se constatar a ocorrência de um maior potencial de flexibilidade nas organizações, a 
racionalidade subjacente ainda permanecia a instrumental, aquela própria das burocracias.

De maneira semelhante, Paes de Paula (2002), a partir da revisão do pensamento de Maurício Tragtenberg, discutiu as relações entre os modos de produção capitalista e as teorias administrativas no contexto da flexibilidade organizacional, demonstrando a persistência das harmonias administrativas e do ethos burocrático na teoria e prática das organizações. Para a autora, a burocracia se transformou para atender às novas demandas mercadológicas e tecnológicas, tornando-se, assim, flexível, reinventando os mecanismos de controle e dominação e originando um mais sofisticado aparelho de cunho ideológico e reprodutor de dominação.

A problemática da dominação burocrática, uma das maiores contribuições de Max Weber, parece ser tema central dentro dessa discussão. Para Prestes Motta (1993, p. 85), “a dominação deve ser entendida como um estado de coisas no qual as ações dos dominados aparecem como se estes houvessem adotado como seu o conteúdo da vontade manifesta do dominante". Assim, apesar de ser uma forma de poder, ela não é idêntica ao poder, na medida em que "poder é a possibilidade que alguém ou algum grupo tem de realizar sua vontade, inclusive quando esta vai contra a dos demais agentes da ação comunitária."

Para Max Weber (1972/1999, p. 191), a dominação deve ser compreendida como "uma situação de fato, em que uma vontade manifesta ("mandado") do "dominador" ou dos "dominadores" quer influenciar as ações de outros. Nessa perspectiva, o autor compreende a dominação como um dos elementos mais importantes da ação social, pois apesar de nem toda ação social apresentar uma estrutura de dominação, 


\section{FLEXIBILIDADE ORGANIZACIONAL E VIVÊNCIAS DE PRAZER-SOFRIMENTO: UM ENSAIO TEÓRICO \\ Monique Nascimento | Eloise Helena Livramento Dellagnelo | Renê Birochi}

na maioria de suas formas, a dominação desempenha um papel considerável. Toda forma típica de dominação, por intermédio da situação de interesses e de uma posição monopolizadora, pode transformar-se em uma dominação autoritária. No entanto, a subsistência de toda dominação depende de sua legitimação. Para o autor, existem três formas de legitimação da dominação: a tradicional, carismática e a racional-legal. Quando a ação social da formação de uma dominação se baseia numa relação racional-legal, a mesma encontra seu tipo específico na burocracia.

Enquanto instrumento das relações de dominação, a burocracia é um poder de primeira categoria para aquele que dispõe do aparato burocrático. Uma vez realizada, a burocracia pertence a um dos complexos sociais mais dificilmente destrutíveis, de tal forma que, onde quer que a burocratização tenha sido levada a cabo, cria-se uma forma quase que inquebrantável das relações de dominação. Os dominados acabam por não prescindir e nem substituir o aparato de dominação burocrático, visto que este se baseia em uma "síntese bem planejada de instrução específica, especialização técnica com divisão do trabalho e firme preparo para exercer determinadas funções habituais e dominadas com destreza" (WEBER, 1972/1999, p.222).

Diante do exposto, ao contrário do que alguns autores como Palmer et al (2007) e Clegg (1998) ${ }^{4}$ vislumbram, sugere-se aqui, em consonância com Paes de Paula (2002), que a flexibilidade organizacional implica na adaptação da burocracia a um novo contexto e não a sua

4 Clegg é apontado por vários autores como importante referência na identificação de evidências empíricas de formas organizacionais pós-modernas. Para o autor, a lógica subjacente às organizações pós-modernas apresenta modos de racionalidade bastante diferentes daqueles até então considerados como possíveis. Clegg (1998) apresenta um referencial de análise destas novas formas organizacionais, ditas pós-modernas. $\mathrm{O}$ autor identifica sete imperativos organizacionais básicos, cuja análise permite identificar lógicas de ação modernista ou pós modernista. Apesar de haver notável significância no trabalho desenvolvido por Clegg sobre a perspectiva pós modernista, há inúmeras contestações devido ao fato de não haver evidências empíricas que possam dar sustentação a tais estudos. 
substituição por organizações pós-burocráticas ou pós-modernas. ${ }^{5}$ Para a autora, da mesma forma que a burocracia da era fordista acaba refletindo as características rígidas do capitalismo monopolista e das teorias administrativas vigentes, no cenário pós-fordista a burocracia incorpora a flexibilidade.

Volberda (1998) ao discutir sobre flexibilidade organizacional ressalta que em ambientes extremamente turbulentos, conforme pode ser encontrado nos dias de hoje, é facilitada a flexibilidade, a qual implica em uma ordem mais elevada de controle para se lidar com a mudança de ambientes. Enquanto formas burocráticas tradicionais com base na hierarquia e compromisso fornecem alguma forma de controle estático em ambientes estáveis, os ambientes flexíveis exigem novas estratégias para conseguir o controle dinâmico. Assim, com base em uma revisão de conceitos, o autor refere que a flexibilidade pode ser considerada como uma maneira de conseguir alguma forma de controle organizacional em ambientes turbulentos.

Segundo Volberda (1998), considera-se que uma organização detém controle quando desenvolve estruturas de gestão e respostas firmes para as mudanças que enfrentam. Em ambientes estáveis, as mudanças tendem a ser incrementais e suficientemente raras para que o desenvolvimento de rotinas gerenciais especializadas seja possível e desejável. Em ambientes extremamente turbulentos, o controle não deriva de rotinas especializadas, mas de capacidade adaptativa. Em contraste com o conceito de controle estático prevalente entre as empresas

5 Thompson (1993, p.190) considera as evidências apresentadas pelo movimento pós-modernista como receitas de solução rápida e declara que "não é a primeira vez que a burocracia foi declarada morta, e as evidências não são muito melhores nesta ocasião, como podemos verificar quando algumas características básicas das organizações burocráticas são examinadas". 
ocidentais, capacidades flexíveis são necessárias para permitir respostas rápidas para mudanças imprevisíveis (VOLBERDA, 1998). —

Nessa perspectiva, Paes de Paula (2002) elucida que diante da necessidade eminente de maior flexibilização frente ao turbulento ambiente de negócios e das exigências atuais do mercado, houve uma adaptação das organizações ao novo contexto. Caso contrário, as formas organizacionais poderiam encontrar certas dificuldades para se manterem competitivas frente às variadas transformações ocorridas.

Os primeiros passos nessa direção foram os programas de reengenharia, o downsizing, a virtualização organizacional, a terceirização, a flexibilização das contratações e outros recursos realizados sob o argumento de que era necessário desburocratizar a organização, tornando-a mais ágil, competitiva, e mais flexível às demandas do mercado. Depois, vieram os programas de flexibilização organizacional, muitos ligados ao paradigma da qualidade total, com suas intenções de implantar a administração participativa e erradicar a hierarquia, através do trabalho em equipe, das células de produção, dos grupos semiautônomos, e do empowerment (DELLAGNELO e MACHADO-DASILVA, 2000; PAES DE PAULA, 2002; ANTUNES, 2003).

Paes de Paula (2002) relata que as teorias administrativas também acabaram se ajustando para atender às demandas da reestruturação produtiva, que requer tecnologias e formas de organização do trabalho mais flexíveis do que as fordistas. Assim, emergiram as soluções pósfordistas, por meio de técnicas de gerenciamento da produção e organização do trabalho toyotistas, as quais se destacaram devido à adequabilidade à nova situação histórica.

Portanto, assim como o fordismo representava o ethos do capitalismo monopolista, o toyotismo reflete à lógica do capitalismo 
flexível, podendo-se considerar que ambos elaboram ideias e práticas que legitimam as necessidades de produção, acumulação, reprodução de suas épocas. Corroborando essa visão, Antunes (2003) refere que o receituário difundido pelo mundo empresarial, bem como a flexibilização e o downsizing, são expressões de uma lógica em que o capital é prevalecido diante da força humana de trabalho, força essa que acaba sendo considerada indispensável apenas para a reprodução desse mesmo capital.

Tenório (2003), em o "Mythos da razão administrativa”, tece uma crítica à razão administrativa explicada ou prescrita pelas teorias organizacionais, valendo-se do mito de Sísifo. Em tal trabalho, o autor lança mão da hipótese de que as teorias organizacionais não passam de mitos de algo que poderia ter acontecido e que não dizem respeito àquilo que realmente acontece no interior dos sistemas sociais organizados ${ }^{6}$. Para o autor, seja com o taylorismo-fordismo, passando pelo comportamentalismo, chegando aos dias atuais com o tema da flexibilização, há a prevalência de um fenômeno: o homem enquanto objeto e não como sujeito. Ou seja, conforme o autor, prevalece uma linguagem de coisificação do homem, que acaba sendo homogeneizado com os demais tipos de recursos: humanos, materiais, financeiros e tecnológicos. Tenório conclui seu trabalho questionando se o atual discurso de flexibilidade ou da automação flexível não seria mais um artifício para impedir a emancipação do homem.

6 Tenório (2003) constrói essa hipótese com base em autores da Escola de Frankfurt e Guerreiro Ramos. Ramos (1981) inicia o primeiro capítulo do livro "A Nova Ciência das Organizações" com a seguinte afirmação: "A teoria da organização, tal como tem prevalecido é ingênua. (...). Na realidade, até agora essa ingenuidade tem sido o fator fundamental de seu sucesso prático. Todavia, cumpre reconhecer agora que esse sucesso tem sido unidimensional e, como será mostrado, exerce um impacto desfigurador sobre a vida humana associada. Não é esta a primeira vez em, em razão de considerações teóricas, se é levado a condenar aquilo que funciona na vida social prática." 
Segundo Moraes (2013), as novas formas de organização relacionadas ao modo de acumulação flexível, aliadas ao desenvolvimento tecnológico acabaram por perpetuar e agravar a dominação e o controle no ambiente de trabalho. De forma dissimulada, o discurso gerencial tem alcançado a subjetividade, requisitando um engajamento subjetivo de maneira mais abrangente. Espera-se, hoje, que os trabalhadores aspirem os objetivos da empresa como se fossem seus, aumentando os riscos de alienação e legitimação da dominação exercida pela organização.

Em oposição ao argumento de que tais avanços tecnológicos e mercadológicos das últimas décadas, proporcionariam ao sujeito dos tempos atuais a chance de tornar-se mestre do seu próprio destino, Enriquez (2000) argumenta que jamais o sujeito esteve tão preso às organizações, tão pouco livre sobre seu corpo, seu modo de pensar, à sua psique. As organizações (nesse caso mais precisamente as empresas) fazem o sujeito acreditar que é um ser livre e criador para colocá-lo em grades sutis.

Antunes (2014) discorre que na subsunção do trabalho ao mundo maquínico, conforme observado nos tempos hodiernos, o trabalho estável, herdeiro do período tayloriano-fordista, vem sendo substituído por diferentes e variados modos de informalidade. Para o autor, a informalidade é concebida quando há ruptura com os laços formais de contratação e de regulação do trabalho. Antunes (2014) refere ainda, que a vigência da mesma, tende a expressar com notável frequência e intensidade, formas de trabalho despojadas de direitos, nas quais percebe-se uma considerável similitude com a precarização.

Conforme Antunes (2014, p.30), ao se analisar o trabalho nas organizações taylorianas-fordistas e nas ditas organizações flexíveis do século XXI, é possível que se observe o surgimento de uma "nova era de 
precarização estrutural do trabalho". Para o autor, a referida era de precarização pode ser vislumbrada a partir de alguns aspectos, a saber: erosão do trabalho contratado e regulamentado dominante no século XX; criação das "falsas cooperativas", com o intuito de dissipar ainda mais a remuneração dos trabalhadores, bem como corroer seus direito e avultar os níveis de exploração de sua força de trabalho; promoção do empreendedorismo como forma ideal de trabalho, mas que tem se configurado, paulatinamente, como forma dissimulada de trabalho assalariado e como uma maneira de proliferar diversos modos de flexibilização salarial, funcional, de horário, ou organizativa e degradação intensificada do trabalho do imigrante em escala global.

Para Antunes (2014), é nesse contexto que os capitais globais exigem o desmonte da legislação social protetora do trabalho, em diversas partes do mundo, avultando o esfacelamento dos direitos sociais que foram arduamente conquistados pelos trabalhadores desde os primórdios da Revolução Industrial.

Diante destes posicionamentos sobre o fenômeno da flexibilidade nas organizações contemporâneas, cabe discorrer sobre o tema do prazer e sofrimento no trabalho para se tecer as considerações propostas neste trabalho.

\section{Vivências de Prazer-Sofrimento no Trabalho}

O estudo aprofundado da relação existente entre o trabalho e seus processos psíquicos teve origem no início do século $\mathrm{XX}$, com uma ampla aplicação dos princípios tayloristas, cujo objetivo era racionalizar o trabalho. Em tal época, o crescente desenvolvimento da indústria e a acentuação da divisão entre concepção e execução do trabalho trouxe 
inúmeros prejuízos à saúde física e mental dos trabalhadores (MENDES, 2007). Atualmente, ainda pode-se observar a existência desses estudos, sendo válido ressaltar, especialmente pela difusão nos últimos anos no Brasil e no mundo, a proposta da Psicopatologia e Psicodinâmica do Trabalho, cujo principal expoente é Cristophe Dejours.

A psicopatologia surgiu na França entre as duas grandes guerras, firmando-se em 1950. Conforme Dejours (1992, p.43), a psicopatologia vislumbra estudar "o que acontece na vida psíquica do trabalhador desprovido de sua atividade intelectual pela organização científica do trabalho". Atualmente, figura como campo da psicodinâmica do trabalho (MENDES, 2007).

A Psicodinâmica do Trabalho é uma abordagem científica cuja epistemologia é de natureza crítica do trabalho. Desenvolvida nos anos 1980, fora inicialmente construída por intermédio de referenciais teóricos da psicopatologia, evoluindo para uma construção própria. A utilização do conceito Psicodinâmica do Trabalho em substituição ao de Psicopatologia do Trabalho ocorreu devido a opção de privilegiar o estudo da normalidade em detrimento da patologia, de tal modo que, importa à Psicodinâmica do Trabalho a compreensão de como os trabalhadores conseguem se manter em certo equilíbrio psíquico, mesmo quando submetidos a situações de trabalho adoecedoras.

Merlo e Mendes (2009) consideram como característica importante da psicodinâmica do trabalho o fato de que ela não visa aos indivíduos isoladamente, mas sim o coletivo. Assim, ao diagnosticar o sofrimento psíquico no trabalho, a psicodinâmica busca intervenções voltadas para a análise da organização do trabalho, a qual os indivíduos estejam submetidos. Os autores ainda relatam que essa abordagem permitiu 
ampliar a visão que responsabilizava apenas os trabalhadores por consequências sobre a sua saúde.

Para a abordagem fundada por Dejours, o trabalho é um local em que o prazer coexiste com o sofrimento. Nessa perspectiva, prazer e sofrimento são indissociáveis, e o trabalho contribui para a subversão do sofrimento em prazer, a partir de condições políticas, éticas e sociais da organização e dos processos de trabalho. De tal forma, compreende-se que tanto o prazer quanto o sofrimento são resultantes de uma combinação da história do sujeito e influenciados pela organização do trabalho (MENDES; MULLER, 2013). Salienta-se ainda, que Ferreira e Mendes (2001, p.494) entendem o constructo prazer-sofrimento como dialético e o definem, como: "uma vivência subjetiva do próprio trabalhador, compartilhada coletivamente e influenciada pela atividade de trabalho".

O termo prazer é oriundo do latim, derivado do verbo: placere, que significa agradar, parecer bem (MENDES; MULLER, 2013). O termo prazer, que se apresenta como um conceito fundamental na Psicodinâmica do Trabalho, é também trabalhado na Psicanálise (FREUD, 1930/2011; MENDES; MULLER, 2013). De acordo com Freud (1930/2011), a atividade humana percorre duas direções: a busca pelo prazer e evitação do desprazer ou sofrimento. Desse modo, o prazer pode ser relacionado à busca de satisfação de desejos apresentados pelo sujeito, podendo ser considerado uma manifestação ocasional, tendo vista as contraposições impostas pela civilização.

Partindo da concepção Freudiana, Alderson (2004, p.254) vislumbra que, "o prazer no trabalho se refere ao estado de bem-estar psíquico que o trabalhador conhece, quando seu trabalho satisfaz seus desejos de reconhecimento, permitindo-lhe assim construir sua 
identidade". Conforme Dejours (2013), o prazer é uma experiência emocional ligada à expansão da subjetividade. Em um jogo, entre o desejo, renúncia e gratificação, o prazer se estabelece, podendo assim, ser considerado um estado, nunca acabado, pois quando a gratificação é alcançada, ela passa a ser substituída por outra, produzindo uma outra busca MENDES; MULLER, 2013).

Mendes e Muller (2013), definem o prazer no trabalho como:

(...) um princípio mobilizador que coloca o sujeito em ação para a busca da gratificação, realização de si e reconhecimento pelo outro da utilidade e beleza do seu trabalho. Este prazer é viabilizado pela mobilização da inteligência prática frente aos constrangimentos da organização do trabalho, da construção do coletivo de trabalho, que envolve regras de ofício, as regras de convivência e de cooperação, provocando com esta mobilização a ressignificação do sofrimento (MENDES; MULLER, 2013, p.290)."

Em síntese, para a psicodinâmica do trabalho, o prazer não está isolado e é considerado mais que um objeto em si. Ou seja, o prazer encontra-se sempre associado ao sofrimento que emerge do confronto com o real, cabendo a organização do trabalho o dever de possibilitar ao trabalhador uma mobilização subjetiva, capaz de evitar o sofrimento e ressignificar sua relação com o trabalho (DEJOURS, 2012b, 2013; MENDES; MULLER, 2013).

Conforme mencionado anteriormente, o sofrimento no trabalho e busca de sua ressignificação é uma temática central à psicodinâmica do trabalho, tendo em vista que sofrimento integra o trabalhar. Partindo de uma concepção freudiana, para Dejours (1992, p. 10), o sofrimento existe quando a organização do trabalho entra em conflito com o funcionamento psíquico dos homens, "quando estão bloqueadas todas as possibilidades de adaptação entre a organização do trabalho e o desejo dos sujeitos". 
Mendes e Morrone (2010) consideram o sofrimento uma vivência individual ou coletiva, diversas vezes inconsciente, de experiências dolorosas como angústia, medo e insegurança, provenientes do conflito entre as necessidades de gratificação entre corpo e mente e a restrição de satisfazê-las pelas imposições das situações de trabalho. Desse modo, em conformidade com os autores, há instalação da vivência de sofrimento quando a realidade acaba não oferecendo as possibilidades de gratificação das necessidades dos trabalhadores.

Todavia, há que se destacar, que o sofrimento não deve ser compreendido como necessariamente patogênico. De acordo com a abordagem desenvolvida por Dejours, um dos possíveis destinos do sofrimento é a criação, tendo em vista que o mesmo pode atuar como propulsor para mudanças. Quando o trabalhador se depara com algum problema que o faz experimentar o fracasso, e busca uma solução como tentativa para aliviar o sofrimento, observa-se o sofrimento criativo (MORAES, 2013).

Para Dejours et al (2014), no sofrimento criativo há uma mobilização subjetiva por parte do indivíduo que possibilita a subversão do seu sofrimento em prazer. Esse investimento subjetivo é potencializado pela inteligência prática, espaço à fala, cooperação e reconhecimento (MORAES, 2013b). No entanto, há necessidade de haver certa liberdade por parte da organização do trabalho para que haja certa negociação entre os desejos do trabalhador e às necessidades da organização.

Quando não há a concessão de certa liberdade por parte da organização do trabalho e esta entra em conflito com o funcionamento psíquico dos trabalhadores, com o investimento na criatividade, bem como frente a outros constrangimentos impostos, inviabiliza-se a transformação do sofrimento. Diante de tais circunstâncias, os 
trabalhadores constroem estratégias, individuais ou coletivas, para não sucumbir à doença. As estratégias de defesa podem ser compreendidas como recursos construídos pelos trabalhadores, para proteção contra os efeitos desestabilizadores do confronto com o real do trabalho, que implicam na minimização ou na recusa da percepção daquilo que faz sofrer (DEJOURS, 2012).

Dejours (2012) elucida que sem tal recusa, seria improvável, e até mesmo impossível, prosseguir na atividade de trabalho. Não obstante, quando instaladas, as defesas tendem a tornarem-se conservadas e protegidas, participando da perpetuação daquilo que tinham por princípio combater, os efeitos psíquicos deletérios. Pode-se observar que a longo prazo, as estratégias de defesa impactam negativamente na saúde mental daqueles que a elas recorrem amiúde. É possível também, haver o esgotamento das estratégias defensivas frente à exacerbação das situações que causam sofrimento.

Desse modo, instala-se o sofrimento patogênico, que pode ser caracterizado pela manifestação de patologias psíquicas e/ou somáticas (MORAES, 2013) e ser relacionado à falta de liberdade oferecida ao trabalhador e de flexibilidade da organização do trabalho, a qual impede que o trabalhador seja considerado sujeito do seu comportamento (DEJOURS et al, 2014). Cabe mencionar, que apesar de não ser possível eliminar o sofrimento no trabalho, pode-se investir em mecanismos que venham a favorecer sua subversão ${ }^{7}$.

Nos últimos anos realizaram-se pesquisas significativos no Brasil, acerca das vivências de prazer e de sofrimento no trabalho. Com o intuito de melhor compreender o conteúdo do conhecimento produzido, bem

7 Ressalta-se que subverter, nesse caso, não implica em anular, ou apagar o sofrimento, "pode-se apenas transformá-lo em sentido e eventualmente em prazer: o prazer da reapropriação do vivido pela ação" (DEJOURS, et al. 2014, p. 86). 
como o panorama de produção científica no país, Mendes e Morrone (2010) realizaram um levantamento bibliográfico das produções científicas brasileiras que abordaram aspectos concernentes às vivências de prazer e de sofrimento no trabalho. Ao realizar o corte temporal do período correspondente a 1998-2007, as autoras levantaram um total de 123 estudos. Apesar de haver uma concentração de tais estudos em profissões relacionadas à área da saúde - agentes comunitários de saúde, enfermeiros, técnicos e auxiliares de enfermagem -, observou-se também a presença de pesquisas abrangendo: trabalhadores da educação, especialmente professores; bancários; profissionais de tele atendimento; servidores públicos; catadores de lixo; costureiros; trabalhadores da construção civil; e pilotos de trem.

Conforme Mendes e Morrone (2010), as vivências de sofrimento no trabalho, em tais pesquisas, foram caracterizadas pela presença de pelo menos um dos seguintes sentimentos: medo; insegurança; insatisfação; desorientação; impotência diante das incertezas e para a promoção de mudanças; estranhamento; vulnerabilidade; frustração, alienação; inquietação; angústia; tristeza; agressividade; desgaste físico e psíquico; desestímulo; desânimo; desvalorização; culpa; tensão; e raiva. Já as vivências de prazer, foram relacionadas aos sentimentos de: reconhecimento; identificação; orgulho pela atividade em si; realização profissional e liberdade.

Além da caracterização das vivências de prazer e de sofrimento no trabalho e na ênfase no caráter dialético de tais vivências, Mendes e Morrone (2010) mencionam que nos estudos levantados, também foram identificadas relações existentes entre características internas do contexto de trabalho e a vivência de sofrimento e de prazer pelo trabalhador. De maneira geral, as vivências de sofrimento foram associadas aos seguintes 
fatores: fragmentação das atividades; rigidez na condução da atividade; pressão interna para cumprimento das metas; supervisão coercitiva; ausência de participação nas decisões; falta de flexibilidade e/ou autonomia; conflitos entre os valores da empresa e os pessoais; excesso de trabalho; longas jornadas de trabalho; insuficiência de pausa e repouso; indisponibilidade de recursos materiais e de pessoas; ambiente de trabalho precário; baixa remuneração; ausência de cooperação; dificuldade em estabelecer relações de confiança; falha de comunicação e ambivalência da relação com o cliente.

As vivências de prazer no trabalho, no levantamento realizado por Mendes e Morrone (2010), por sua vez, foram vinculadas a fatores, como: desenvolvimento de atividades que requerem iniciativa; capacidade de argumentação e comunicação verbal; trabalho dinâmico; visualização dos resultados do trabalho; realização de atividades com começo, meio e fim; possibilidade de tomar decisões; autonomia; liberdade; remuneração salarial satisfatória; atitudes de cooperação na equipe e espaços de discussão.

Entre os estudos mencionados por Mendes e Morrone (2010), destaca-se a pesquisa realizadas por Souza e Mendes (2006) e Mendes e Tamayo (2001). Souza e Mendes (2006), em pesquisa realizada em cooperativas de reciclagem, relacionaram as vivências de prazer à flexibilidade organizacional, pois ao não manter os trabalhadores presos ao trabalho prescrito, e ao possibilitar uma abertura para mobilização subjetiva, acaba-se por sustentar o trabalho real. Vale salientar, que corroborando essa visão, Dejours et al. (2014) referem que a organização do trabalho deve ser flexível para que se consiga oferecer um trabalho equilibrante aos indivíduos, pois é necessária a existência de uma maior liberdade para que os trabalhadores possam ser considerados sujeitos de 
seu próprio comportamento e que condições adoecedoras sejam ressignificadas.

Mendes e Tamayo (2001) relatam que algumas pesquisas realizadas em psicodinâmica do trabalho, indicam que as vivências de sofrimento aparecem associadas à divisão e à padronização de tarefas, com baixa utilização do potencial técnico e da criatividade; rigidez hierárquica, com excesso de procedimentos considerados burocráticos, ingerências políticas, centralização de informações, não reconhecimento, alienação e falta de participação nas decisões; e pouca perspectiva de crescimento profissional. Os autores ainda sustentam que os valores da organização podem vir a ser fontes de sofrimento no trabalho quando acabam promovendo a ausência de negociação de normas, criação de verdades que não podem ser questionadas e a naturalização de situações.

No ano subsequente ao estudo realizado por Mendes e Morrone (2010), Moras e Vasconcelos (2011) desenvolveram uma pesquisa com sete empresas situadas no Polo Industrial de Manaus, acerca da dimensão subjetiva do trabalho com automação. Em tal pesquisa, na dinâmica entre as relações de trabalho, o sofrimento foi associado: ao autoritarismo, violência verbal e coação, por parte dos superiores hierárquicos; e a existência de competição e ao individualismo entre os pares. Circunstâncias que poderiam promover a ressignificação do sofrimento, como o reconhecimento e a autonomia, foram percebidos de modo limitado, dificultando o uso da inteligência prática e a subversão do prazer. Para as autoras, tal estudo evidenciou que o sofrimento no trabalho tem se tornado patogênico, inclusive em organizações que utilizam da automação e promovem um discurso de superação ou diminuição do sofrimento no trabalho, a partir do uso de novas tecnologias. 
Frente ao exposto, percebe-se, uma possível articulação entre vivências de prazer-sofrimento e flexibilidade organizacional, a qual propõe-se discutir na sequência

\section{Vivências de Prazer-Sofrimento e Flexibilidade Organizacional: Articulações Possíveis}

A partir de uma concepção dejouriana a respeito do prazer e sofrimento, entende-se que as organizações não são apenas locais em que se trabalha, mas também são locais em que o prazer coexiste com o sofrimento, ou seja, não há como eliminar o sofrimento do trabalho, é possível, contudo, que se proporcione mecanismos de subversão desse sofrimento. Argumenta-se que, embora o discurso da flexibilidade organizacional enuncie a construção de novos espaços produtivos, nos quais prevaleça a autonomia, a criatividade e a liberdade do trabalhador na tomada de decisão, o que ocorre efetivamente é o desenvolvimento de novos mecanismos de controle, os quais são muito mais sutis e imperceptíveis, tornando o sujeito preso em jaulas agora invisíveis.

De acordo com Dejours et al, (2014), não há uma organização do trabalho única, que seja uma boa opção para diminuir a carga psíquica do trabalho para todos os trabalhadores, tal fato dependerá das necessidades individuais de cada sujeito. Segundo os autores, para que um trabalho fatigante seja transformado em um trabalho estruturante, é necessário que a organização do trabalho seja flexível, no sentido de promover liberdade ao trabalhador; liberdade esta que inclui a possibilidade de cada trabalhador rearranjar seu modo operatório e encontrar maneiras de trabalhar, de forma que lhes seja possível vivenciar prazer. Todavia, Paes de Paula (2002) elucida que a ideologia da harmonia administrativa, 
também subjacente às formas flexíveis de organização, tende a favorecer a produtividade e a ordem nas organizações e mantém-se longe de promover a liberdade efetiva do trabalhador.

Enriquez (2000) enfatiza que enquanto as estruturas organizacionais anteriores privilegiavam uma tentativa de controle do pensamento, da psique e, de uma forma semelhante um controle do corpo, a busca pelo controle sobre o pensamento é atualmente reforçada. Segundo o autor, nos tempos hodiernos, intenta-se controlar a psique de uma forma mais sutil - os trabalhadores se identificam com a empresa e com seus chefes, tornando-se serviçais voluntários, com gozo na submissão -, e o controle sobre o corpo torna-se essencial. Assim, o controle social cede à fantasia da totalidade, ainda que o controle total, salvo em casos raros, jamais tenha existido (ENRIQUEZ, 2000).

Em conformidade com Gaulejac (2014), enquanto no modo tayloriano-fordista de produção, focava-se na canalização da atividade física a fim de tornar corpos úteis, na era da flexibilização, a preocupação sobre os corpos é deslocada para a transformação da energia libidinal em força de trabalho. Assim, o controle rigoroso dos corpos é substituído pela mobilização psíquica a favor da empresa, ou nas palavras de Gaulejac (2014, p. 117-118), "mais do que enquadrar os corpos, procura-se canalizar as pulsões e mobilizar os espíritos". Na devoção de corpo e alma, os desejos dos trabalhadores são confundidos com os da empresa e corre-se o risco de os mesmos agirem como se fossem uma extensão dela. Circunstância em que a alienação é intensificada e a dominação exercida pela organização tende a ser legitimada.

Apesar do frequente discurso de flexibilidade organizacional associado à maior liberdade oferecida ao trabalhador, e por consequência a um aumento da possibilidade de vivências de prazer no ambiente de 
trabalho, frente ao exposto, pode-se perceber a incessante tentativa por parte das empresas, de conseguir alcançar de controle dos corpos e mentes humanas. Ainda que o controle total permaneça no imaginário, devido a não submissão do inconsciente humano, tenta-se sobremaneira obtê-lo. Ao contrário da lógica taylorista-fordista já considerada despótica, na lógica da organização flexível, com sua aparência de gestão participativa e envolvente - e possivelmente mais manipulatória -, a liberdade individual do trabalhador torna-se uma liberdade que não transcende à aparência.

Conforme destacado por Paes de Paula (2000), por exemplo, mudanças no mundo do trabalho conduziram à destruição dos coletivos de trabalho e à degradação de relações intersubjetivas, assim, de acordo com a autora, os modelos organizacionais atuais acabaram por aperfeiçoar os meios anteriores de dominação, promovendo, condições de trabalho degradantes física e psicologicamente. Tenta-se sequestrar a subjetividade, o tempo e os corpos dos trabalhadores, reduzindo-se a esfera organizacional às regras objetivas de convivência, evitando o desenvolvimento de um trabalho salutar e promovendo um ambiente de degradação psicológica e sofrimento dentro das organizações.

Nesse cenário, Moraes (2013) refere que nos últimos decênios, o sofrimento no trabalho tem sido agravado e se tornado patogênico. Corroborando, Dejours e Bégue (2010) discorrem a respeito do maior espaço adquirido pelo sofrimento patogênico e pelo consequente avanço das patologias do trabalho, nas últimas décadas. Para os autores, tais formas de adoecimento, que possuem a solidão em comum - classificadas pelos autores como patologias da sobrecarga, pós-traumáticas, do assédio, depressões e suicídios - apontam para o agravamento do sofrimento no contexto de trabalho. 
A reestruturação produtiva da era da acumulação flexível não eliminou também os problemas da precarização do trabalho. Pelo contrário, acabou por reproduzir a desigualdade social, um monumental desemprego, e agravou ainda mais a precarização do trabalho já existente (ANTUNES, 2003). Vivencia-se uma subproletarização intensificada, presente na expansão do trabalho temporário, "part in time", precário, subcontratado, "vinculado à economia informal", entre tantas outras formas existentes. Com a flexibilização da produção também se vive a flexibilização dos direitos trabalhistas. Direitos e conquistas arduamente alcançadas pelos trabalhadores são esfacelados, substituídos e colocados a serviço do capital (ANTUNES, 2014). Circunstância perversa e repleta de efeitos deletérios ao trabalhador, que pode ser observada em inúmeros países, inclusive, no Brasil. Salienta-se que a "flexibilização das formas de emprego" - entenda-se aqui, precarização das formas de emprego conduz à individualização, ao desenvolvimento de condutas desleais entre pares e a aniquilação de realizações solidárias.

Dessa forma, compreende-se que a acumulação flexível se encontra longe de promover a democratização das relações sociais, e o trabalho submetido a essa lógica está distante de ser um meio de libertação, pois certamente, "o trabalhador submetido à necessidade de ganhar o seu pão não é livre" (DEJOURS, 2012, p. 171). Distante de propiciar um caminho ou movimento que visa libertar da dominação, os modelos organizacionais atuais acabaram por aperfeiçoar os meios anteriores de dominação, promovendo, condições de trabalho degradantes física e psicologicamente. Assim como para Dellagnelo e Machado-da-Silva (2000) não foi possível encontrar ruptura entre as formas flexíveis de organização com o modelo burocrático, pode-se afirmar que a sofisticação dos mecanismos de controle desenvolvidos nessas organizações implica 
na legitimação de um discurso burocrático adaptado agora ao contexto econômico da acumulação flexível.

Acredita-se que, atentar às consequências à subjetividade dos sujeitos e ao agravamento das vivências de sofrimento no trabalho no cenário atual, consiste assim em um importante alerta a contribuir dentro da perspectiva crítica dos estudos organizacionais (FARIA, 2009), tarefa que pode ser realizada a partir da Psicodinâmica do trabalho. No entanto, para tal feito, necessita-se que os estudos organizacionais não apenas reconheçam a interdisciplinaridade que lhes é intrínseca, mas que busquem em outras lentes teóricas novos diálogos entre as interfaces com demais áreas do conhecimento. Desconsiderar tais fatos pode significar assumir a parcialidade no desenvolvimento de teorias organizacionais, produzindo-se, dessa forma, um saber que não seja reflexivo, mas ao contrário, um saber que seja um receituário para aumentar a produtividade, perpetuar as instrumentalidades e ideologias das harmonias administrativas e, consequentemente, manter-se cada vez mais distante de promover liberdade de fato ao trabalhador.

\section{Referências}

AKTOUF, O. Administração e teorias das organizações contemporâneas: rumo a um humanismo radical crítico? Organizações e Sociedade, O\&S, Salvador, v. 8, n. 21, p. 13-33, ago. 2001.

ALDERSON, M. La psychodynamique du travail: objet, considerations épistémologiques et premisses théoriques. Santé mentale au Québec, Érudit, Canadá, v. 29 n.1, p. 243-260, 2004.

ANTUNES, R. Adeus ao Trabalho? Ensaios sobre as metamorfoses e a centralidade do mundo do trabalho. 9ª Edição. São Paulo, Cortez, 2003. 
CLEGG, S. R. As Organizações Modernas. Oeiras: Celta Editora, 1998.

DELLAGNELO, E. H. L.; MACHADO-DA-SILVA, C. Novas formas organizacionais: onde se encontram as evidências empíricas de ruptura com o modelo burocrático de organizações? Organizações e Sociedade, O\&S, Salvador, v.7, n.19, p. 19-33, set. /dez.2000.

DEJOURS, C. J. A Loucura do Trabalho: estudo de psicopatologia do trabalho. 5ª Edição Ampliada. São Paulo, Cortez - Oboré, 1992.

DEJOURS, J. C. A Sublimação, entre prazer e sofrimento no trabalho. Revista Portuguesa de Psicanálise. Lisboa, v.33, n.2, p.9-28, 2013.

DEJOURS, C. Trabalho Vivo: Trabalho e emancipação (Tomo II). Brasília: Paralelo 15, 2012.

DEJOURS, J. C.; ABDOUCHELI, E.; JAYET, C. Psicodinâmica do

Trabalho: contribuições da escola Dejouriana à análise da relação prazer, sofrimento e trabalho. 1aㅡ Edição. São Paulo, Atlas, 2014.

DEJOURS, J. C.; BÉGUE, F. Suicídio e Trabalho: o que fazer? Brasília: Paralelo 15, 2010.

ENRIQUEZ, E. O Indivíduo Preso na Armadilha da Estrutura Estratégica. 403 In: MOTTA, F. P.; FREITAS, M. E. Vida Psíquica e Organização. Rio de Janeiro: FGV, 2000.

FERREIRA, M. C.; MENDES, A. M. “Só de pensar em vir trabalhar já fico de mau humor": atividade de atendimento ao público e prazer-sofrimento no trabalho. Estudos de Psicologia, vol.6, n.1, p. 93-104, 2001.

FARIA, J. H. de. Teoria crítica em estudos organizacionais no Brasil: o estado da arte. Cad. EBAPE.BR, Rio de Janeiro, v. 7, n. 3, p. 509-515, set. 2009.

FREUD, S. O Mal-Estar na Civilização (1930). São Paulo: Companhia das Letras, 2011. 
GAULEJAC, V. de. Gestão como Doença Social: Ideologia, poder gerencialista e fragmentação social. São Paulo: Ideias \& Letras, 2014.

MARZANO, M. Travail et compulsif apagamento de la subjectivité: L'hyperactivité comme fuite. Travailler, Paris, v 1, n. 11, p. 7-24, 2004.

MENDES, A. M. (Org.). Psicodinâmica do Trabalho: teoria, método e pesquisas. São Paulo: Casa do Psicólogo, 2007.

MENDES, A. M; ARAÚJO, L. K. R. Clínica Psicodinâmica do Trabalho: o sujeito em ação. Curitiba: Juruá, 2012.

MENDES, A M.; MULLER, T. da C. Prazer no Trabalho. In: VIEIRA, F. de O.; MENDES, A. M.; MERLO, A. R. C. (Org.). Dicionário Crítico de Gestão e Psicodinâmica do Trabalho. Curitiba: Juruá, 2013. p. 289-296.

MENDES, A. M.; MORRONE, C. F. Trajetória Teóricas e Pesquisas

Brasileiras sobre Prazer e Sofrimento no Trabalho. In: MENDES, A. M.;

MERLO, A. R. C.; MORRONE, C. F.; FACAS, E. P. (Org.). Psicodinâmica e

Clínica do Trabalho: temas, interfaces e casos brasileiros. Curitiba: Juruá

Editora, 2010, p. 29-52.

MENDES, A. M.; TAMAYO, A. Valores organizacionais e prazersofrimento no trabalho. Psico-USF, v.6, n.1, p.39-46, jan./jun. 2001.

MERLO, A. R. C.; MENDES, A. M. Perspectivas do Uso da Psicodinâmica do Trabalho no Brasil: teoria, pesquisa e ação. Cadernos de Psicologia Social e do Trabalho, v.12, n.2, p.141-156, 2009.

MORAES, R. D. de. Sofrimento Criativo e Patogênico. In: VIEIRA, F. de O.; MENDES, A. M.; MERLO, A. R. C. (Org.). Dicionário Crítico de Gestão e Psicodinâmica do Trabalho. Curitiba: Juruá, 2013b. p. 415 - 419.

MORAES, R. D. de; VASCONCELOS, A. C. L. Subjetividade e Trabalho com Automação: estudo no pólo industrial de Manaus. Manaus: EDUA, 2011. 
MOTTA, F. C. P. Revisitado por VASCONCELLOS, I. F. G. de. WOOD, T. Jr. Controle Social nas Organizações. Revista de Administração de Empresas, v33, n.5, p.68-87, set. /out. 1993.

PAES DE PAULA, A. P. Tragtemberg revisitado: as inexoráveis harmonias administrativas e as burocracias flexíveis. Revista de Administração Pública, v. 36, n. 1, p. 127-144, jan./fev. 2002.

PAGÉS, M. et al. O poder das Organizações. São Paulo: Atlas, 1993.

PALMER, I.; BENVENISTE, J.; DUNFORD, R. New Organizational forms: towards a generative dialogue. Organization Studies, v. 28, n. 12, p. 47-60, jun. 2007.

RAMOS, A. G. A Nova Ciência das Organizações. Rio de Janeiro: FGV,1981.

SENNETT, R. A Corrosão do Caráter: as consequências pessoais do trabalho no novo capitalismo. Rio de Janeiro: Record, 1999.

SOUZA, C. M.; MENDES, A. M. Viver do lixo ou no Lixo: A saúde no trabalho de catadores de material reciclável em Brasília. Revista de

Psicologia: Organizações e Trabalho, v.6, p.13-41, jul. /dez. 2006.

TENÓRIO, F. G. Flexibilização organizacional, mito ou realidade? Rio de Janeiro: FGV, 2002.

THOMPSON, P. Postmodernism: fatal distraction. In: HASSARD, J.; PARKER, M. Postmodernism and Organizations. London: Sage Publications, 1993. 
FLEXIBILIDADE ORGANIZACIONAL E VIVÊNCIAS DE PRAZER-SOFRIMENTO: UM ENSAIO TEÓRICO

Monique Nascimento I Eloise Helena Livramento Dellagnelo I Renê Birochi

VOLBERDA, H. W. Building the flexible firm: bow to remain competitive. New York: Oxford University Press, 1998.

WEBER, M. Economia e Sociedade: fundamentos da sociologia compreensiva (1972). 4. ed Brasília, DF: Editora Universidade de Brasília, 1999. v.1.

Submetido em: 25/01/2018

Aprovado em: 05/03/2018 